\title{
The Necessary Gap: Chaos as Self in The Education of Henry Adams
}

T $\mathrm{N}$ scientific texts the connections among concept, culture, and self 1 are implicit, encoded in metaphors and heuristics. In The Educa-
tion of Henry Adams they are explicitly the subject of Adams's dynamic theory of history. According to the dynamic theory, the curve of history can be charted as the attraction between the human mind and the explosive forces of a supersensual chaos. Modern consciousness differs from earlier modes of thought because it has absorbed more of the chaos within itself. In The Education, chaos is not just connected with the self; in an important sense, it is the self. Whereas my discussion of the scientific tradition started with objectivity and moved toward subjectivity, my comments about The Education will start with how subjectivity is constituted within the text and move toward its entanglement with scientific concepts.

Privately printed by Adams in 1907, The Education marks a midpoint between Kelvin's mid-nineteenth-century vision of entropy as universal dissipation and Shannon's reconceptualization of it as information in the mid-twentieth century. Anticipating Shannon, The Education recognizes the possibility that chaos may be positive force rather than negative uncreation. But enough of the older attitudes toward disorder still cling to it so that chaos is represented within The Education as an intensely ambivalent, as well as highly charged, concept. Even whether it is something rather than nothing, a pres- 
ence rather than an absence, remains in doubt. This doubt is reflected and reinscribed in the constitution of a "real" self, which paradoxically is a presence constituted through the assertion of its absence. Signifiers of the self include gaps, holes, and voids in the narrative. In the resulting interplay between presence and absence, meaning derives as much from what is not said as from what is said. "The result of a year's work depends more on what is struck out than on what is left in," Adams wrote in The Education. It also depends more "on the sequence of the main lines of thought, than on their play and variety" (I 973: 389).

According to what has been left in, the sequence appears to be this. Adams self-consciously conceived of The Education as marking the rupture between the ordered certainties of the Newtonian synthesis and the chaotic multiplicities that he saw as characteristic of the twentieth century. This division is inscribed into the form of The Education. The first half records Adams's repeated attempts to launch himself in the world, working from a conception of the universe as unity, linearity, and fixed truths; the second half finds him searching for, and eventually articulating, a theory that can explain the world as it actually exists-an anarchistic multiverse of chaos, complexity, and relativism. From this perspective, The Education seems to be an exemplary account of one man's initiation into the technological and social contexts that form the cultural background for the later emergence of the sciences of complexity.

Yet almost immediately, complications arise in this simple picture. Henry Adams himself is not a unit but a multiple. There is the character whom Adams describes in the Preface as a "manikin," of interest only because of the clothes he wears (p. xxx); the narrator, who writes retrospectively about Adams the character; and the author, who constructs both narrator and character as well as the clothes they wear.' If we choose to omit the author and arrange the narrator and character along a linear sequence, we can say (as various commentators have said) that the gap between the naive perspective of the character and the educated hindsight of the narrator continually

'The division into author, character, and narrator is conventional enough to be often noticed; see, for example, Martin, 1981: I 19. The clothes reference is of course an allusion to Carlyle's Sartor Resartus, to which Adams alludes throughout The Education. 
narrows as the text progresses, until by the end the character espouses a view very close to the narrator's. ${ }^{2}$ By the nature of textuality, however, the gap never quite closes. As the presumed present-tense existence of the narrator is translated into the past tense of the character, the character stands as a marker for what was, forever deferred and different from the narrator.

This complication is itself a simplification; but it is nevertheless useful, for it demonstrates how far the text is from a merely linear sequence. The narrator's retrospective view creates an undertow that pulls against the character's naiveté, transforming the narrative into a strongly nonlinear progression. On the opening page, for example, after a circuitous sentence giving the place and time of his birth, Adams muses on whether his distinctive heritage was an advantage or a handicap. Characteristically he finds himself, even in retrospect, unable to decide. He knows only that he "could not refuse to play his excellent hand." He asserts that he "accepted the situation as though he had been a party to it, and under the same circumstances would do it again, the more readily for knowing the exact values." Apparently the values are not so exact, however, for within a few lines he remarks that "as it happened, he never got to the point of playing the game at all; he lost himself in the study of it, watching the errors of the players" (p. 4).

If we think of the narrator as an extrapolation into the present of Adams the character, there is an obvious contradiction in his claims that Adams did not refuse to play and that he only observed. The contradiction is intensified by the qualifying phrase "as it happened," for the phrase insists on the actuality of the narrator's observer status, even as it grounds itself in a historicity appropriate to the character's player status. The construction implies that in some sense the narrator and character are at once separated in time and simultaneously present, part of a linear sequence and enfolded together into a convoluted space that defies linearity. Given this space, it is simplistic to the point of distortion to say that The Education records Adams's initiation into chaos. Rather, chaos is represented

'Judith Shklar discusses the narrowing gap between narrator and character in "The Education of Henry Adams by Henry Adams," Daedalus 103 (1974): 59-66, especially p. 6I. 
as always already present within a complex dynamic of revelation and concealment.

In an often-cited letter to Henry James, Adams called The Education "a mere shield of protection in the grave," adding, "I advise you to take your own life in the same way, in order to prevent biographers from taking it in theirs." ${ }^{3}$ The remark suggests that as one life is scripted into the text, another is leached away. But Adams does not imagine himself dying into the finished text, as Nabokov's protagonist Van Veen claims in Ada. On the contrary, the inscripting process is to provide a shield, a protective covering that conceals even as it marks a rupture between Adams the author and the character/narrator of The Education. What does this rupture signify? On the surface, it makes the same point Adams stresses in the Preface, that the character we see in The Education is no self-revelation of an egoistic individual but a manikin who has the "same value as any other geometrical figure of three or more dimensions, which is used for the study of relation" ( $\mathrm{p} . \mathrm{xxx}$ ). More subtly, the rupture constitutes as a possibility the belief that some authorial self lingers beyond the reach of textuality, autonomous and self-determined in a way that the character obviously is not. Thus the very act of concealing a "real" self is also a constituting gesture that establishes its existence. It is in this sense that the absence-or more correctly, the suppression-of self affects the form of the text as much as if its presence were emblazoned on every page. ${ }^{4}$

The "real" self, manifesting itself within the text as absence, rupture, or gap, further complicates the linear flow of the narrative and

'Dated 6 May 1908, the letter appears in Adams, 1938:495.

"Candace Lang, in "Autobiography in the Aftermath of Romanticism," Diacritics I 2 (I982): I-1 2, cogently criticizes recent theoretical treatments of autobiography for assuming that an authorial self, however problematic its relation to an autobiographical text, exists outside the text, independent of writing and textuality. She argues that such essentialist notions of an authorial self are naive, because the self is always already textualized in the Derridean sense. I accept this view. In writing about a "real" self, I mean to imply not a self that is essential in fact but one posited within the text as beyond the reach of textuality. That such a self is itself a fabrication of the text is assumed as self-evident. For a reading of The Education that applies deconstructive premises to Adams's construction of a self, see John Carlos Rowe's provocative study Henry Adams and Henry James (1 976). Rowe asserts that in "the context of Adams's thought, the conventional notions of 'author' and 'subject' cannot be sustained" (p. 122). 
punctuates the accretion of the inscripted self, rendering its evolution discontinuous or indeterminate. Perhaps the chapter that illustrates this process most clearly is "Darwinism." In his attempt to substantiate Darwinist claims for unbroken continuity within evolution, Adams confronts his own evolution as an individual. He discovers that the fossil record used to support Darwin's theory is incomplete and sometimes contradictory. Working strictly from the evidence, he concludes that he "could prove only Evolution that did not evolve; Uniformity that was not uniform; and Selection that did not select" (p. 23I). Forced by this lack of evidence to ask why he wanted to defend Darwinism in the first place, he decides that he "was a Darwinian for fun" (p. 232), and that as soon as another new idea arrived, he would "drop off from Darwinism like a monkey from a perch." Embedded in this play of wit is a sobering conclusion - that the "idea of one Form, Law, Order, or Sequence had no more value for him than the idea of none; that what he valued most was Motion, and that what attracted his mind was Change" (p. 23I). Since Adams has until this point represented himself as the champion of Law, Order, and Sequence, the conclusion that his mind is attracted by change seems to call for a radical reassessment of who he is.

Instead we are presented with a suture within the text which joins Adams's past and present selves. Significantly, the sequence reestablished by this suturing is not a smooth continuum. Although the suture succeeds in stitching past to present, it also leaves a visible scar, testimony to the depth of the rupture. What caused the rupture we can only infer, since it lies in shadow, hinted at rather than directly stated. Nevertheless, it proves to be a powerfully attractive force for Adams. "Psychology was to him a new study and a dark corner of education. As he lay on Wenlock Edge, with the sheep nibbling the grass close about him as they or their betters had nibbled the grass-or whatever there was to nibble-in the Silurian kingdom of Pteraspis, he seemed to have fallen on an evolution far more wonderful than that of fishes" (p. 23I).

Confronting the possibility that the multiplicity he has always fought against is not just an external force but an internal one as well, he decides that he "did not like it; he could not account for it; and he determined to stop it." He fortifies himself with the idea that 
never "since the days of his Limulus ancestry had any of his ascendents thought thus. ... Out of his millions and millions of ancestors, back to the Cambrian mollusks, every one had probably lived and died in the illusion of Truths which did not amuse him, and which had never changed." When this unbroken chain of antecedents had practiced resistance, it was with the understanding that values were fixed points. They might be wrong, but they never doubted there was an ultimate truth. Into this continuous sequence, stretching to and beyond the prehistoric horizon, a schism erupts in the form of Adams. "Henry Adams was the first in an infinite series to discover and admit to himself that he really did not care whether truth was, or was not, true. He did not even care that it should be proved true, unless the process was new and amusing" (pp. 23I-232).

Now comes the suture. Faced with the recognition that he himself is the catastrophe that disrupts sequence and gives the lie to continuous evolution, he is determined to fold under this multiplicitous self that has momentarily emerged. "He had no notion of letting the currents of his action be turned awry by this form of conscience. To him, the current of his time was to be his current, lead where it might. He put psychology under lock and key; he insisted on maintaining his absolute standards; on aiming at ultimate Unity." Although his quest for unity will continue, the narrator now believes that it derives not from innate nature but from will. "The Church was gone, and Duty was dim, but Will should take its place, founded deeply in interest and law" (p. 232). Where does this will originate? Perhaps in Adams the character, as he struggles to merge the current of his thought with the current of his time; perhaps in Adams the narrator, concerned to stitch together the bits and pieces of his recollections into recognizable garments (how arbitrary these seams can sometimes be is demonstrated in the next paragraph, when the narrator turns from currents to currency); or perhaps even in Adams the author, for the suture hides from view a psychology at odds with both character and narrator, thus simultaneously creating a third self and projecting it beyond the reach of textuality.

As I reread the chapter, realizing that the suture exists, I am struck by the deviousness of this text. For on the opening page, I find Adams declaring essentially the same sentiments that later provide material for a crisis. "The ideas [of Darwinism] were new and 
seemed to lead somewhere-to some great generalization which would finish one's clamor to be educated. That a beginner should understand them all, or believe them all, no one could expect, still less exact. Henry Adams was Darwinist because it was easier than not. . . . He was ready to become anything but quiet. As though the world had not been enough upset in his time, he was eager to see it upset more." Moreover, the narrator admits that Adams "cared nothing about Selection, unless perhaps for the indirect amusement of upsetting curates" (pp. 224-225). Why do these lines have such a different effect than the later realization that he "was a Darwinian for fun"? Partly because they come as prologue rather than conclusion. Adams is a "beginner," and although he is "eager to see [the world] upset more," his desire is presumably on the side of scientific truth rather than against it. Partly too because there is the strong suggestion that his foray into Darwinism is part of a larger approach to truth, or at least to "some great realization that would finish one's clamor to be educated." When the sequence leads to rupture rather than closure, one is left with the impression that something out of the ordinary has happened, something Adams could not reasonably have expected. And yet when I return to the chapter's beginning with foreknowledge of the end, I can see plainly enough that it was all there in the beginning, had I only known how to read it. Which is, of course, precisely the perspective from which the narrator writes.

The chapter demonstrates, then, that the text is informed by two systems of encoding-one embodying the forward, linear perspective of the character, the other giving the backward, retrospective view of the narrator. For critics, this double encoding makes argument by quotation hazardous in the extreme. Depending on the context in which quotations are embedded, one set of codes can be suppressed in favor of another, so that the same words can have not just different but opposite import. Add the further complexities introduced by ruptures, and one can sympathize with the narrator's complaint that no one "means all he says, and yet very few say all they mean, for words are slippery and thought is viscous" (p. 45 I). In the face of these uncertainties, commentators on The Education have looked for ways to stabilize their interpretations by concentrating on large structural blocks or, if they remain on the level of sentences, by 
looking for consistent patterns repeated throughout the text. Yet even here one's grasp on the results is precarious, for in a rhetoric so full of abrupt turns, it is easy to shoot off in one direction while the text turns in another.

Yet the turns themselves form a pattern. The Education is testimony to Adams's exquisite sense of form, as he comes close to admitting in one of the rare passages in The Education where he comments specifically on his writing. "The pen works for itself, and acts like a hand, modeling the plastic material over and over again to the form that suits it best. The form is never arbitrary, but is a sort of growth like crystallization, as any artist knows too well; for often the pencil or pen runs into side-paths and shapelessness, loses its relations, stops or is bogged. Then it has to return on its trail, and recover, if it can, its line of force" (p. 389). Following the maxim "form is never arbitrary," I want to sketch out a pattern that generalizes the observations I have made so far. I shall proceed by way of two commentaries on The Education, one structural and one syntactic.

The first is James M. Cox's article "Learning through Ignorance: The Education of Henry Adams" (1980). Recalling that a dynamo is constructed of two magnetic poles across which a current arcs, Cox points out that bipolarity is everywhere in Adams's work. It is inscribed, for example, in the old and new towers of Chartres that Adams analyzes in Mont-Saint-Michel and Chartres (I9I3); it appears again in the contrast between the femininity of the Virgin's cathedral at Chartres and the masculinity of Saint-Michel; it is written into the relation between Mont-Saint-Michel and Chartres as a study of twelfth-century unity and The Education as an exploration of twentieth-century multiplicity; and it is inscribed again in The Education, with its bifurcated structure broken in half by the twenty-year gap intervening between "Failure" and "Twenty Years After." Cox suggests that we think of The Education as a kind of textual dynamo, with a current crackling back and forth across the gap in a dynamic connection that defeats any static or linear conception of the narrative. Although Cox is not concerned specifically with the relation between character and narrator, one could extend the image to them. At the same time that the narrator's retrospective knowledge surrounds the character's naiveté and gives it an ironic 
inflection, the character's ignorance of outcomes interpenetrates the narrator's knowledge, imparting to it a dynamic uncertainty that belies his posterior position.

Without acknowledging the work of Cox, Linda A. Westervelt provides an important corollary in her analysis of sentence construction in The Education ("Henry Adams and the Education of His Readers," 1984). She points out that key passages are often constructed as compound complex sentences, with independent clauses connected by "but." Westervelt argues that the two halves of these sentences do not cancel each other; rather they create a dynamic tension, making it impossible to decide which assertion is correct. On this view the dynamo is something more than an object represented within The Education, something more even than the expansive metaphor it becomes in Adams's dynamic theory of history. It is the motor that drives the narrative, from the microcosmic level of individual sentences to the macrocosmic level of the large structural blocks. Combining the work of Cox and Westervelt, one could argue that in the dynamo Adams found a structure, a syntax, and a paradigm all at once.

A strand in Westervelt's work, however, goes beyond and qualifies this picture. The balanced antitheses of the sentence structure create an unpredictability that makes it impossible to predict the sequence of thought. If a linear extrapolation appears likely or certain, it is nearly always a setup, an invitation to catastrophe. ${ }^{6}$ We are told, for example, that Clarence King, with "ordinary luck," would "die at eighty the richest and most many-sided genius of his day" (p.

'It has been pointed out to me, by a reader who evaluated this book for Cornell University Press, that a dynamo can act either as a generator or as a motor, depending on whether mechanical energy is converted to electricity or electricity to mechanical energy. Adams does not explicitly comment on this duality, but it is entirely appropriate to his ambiguous construction of the text as a dynamo in which it is uncertain in which direction the lines of force run.

"David Marcell, in "Henry Adams's Historical Paradigm: A Reexamination of the Major Phase" (in Hague, I964:127-I4I), comments that this predictable disruption of sequence is itself a unifying principle. "The Education itself becomes unified, paradoxically, by this recurring pattern of logical assumptions and expectations rudely shocked by the caprice of events and the rush of experience" (p. r35). He also argues that the "only unity left was consciousness. . . Adams had, in fact, been compelled to write his autobiography out of the need to explore the nature of consciousness and its relation to history" (p. I 36). 
3 3 ). Later we learn he in fact died a pauper, ignored and scorned by all but a few loyal friends. So pervasive are discontinuities of this kind that one of the narrator's most characteristic activities is suturing, trying to stitch together a past and a present that have been torn apart and can be fitted together only with difficulty.

At moments of transition, the admission that suturing is necessary comes close to the surface. After the end of the Civil War, for example, the narrator remarks that when Adams "sat down again at his desk in Portland Place before a mass of copy in arrears, he saw before him a world so changed as to be beyond connection with the past" (p. 209). England itself is in need of suturing, for it "was a social kingdom whose social coinage had no currency elsewhere" ( $p$. 203). The cream of English society "could teach little worth learning, for their tastes were antiquated and their knowledge was ignorance to the next generation" (p. 202). English arts and letters were no better. According to the narrator, English thought was as chaotic as the English drawing room, consisting of "bits and fragments of incoherent furnitures which were never meant to go together, and could be arranged in any relation without making a whole, except by the square room" (p. 212). English art was merely a "garden of innate disorder called taste" (p. 214). America was, if possible, worse. When Adams returns to his native land, he decides that one "profession alone seemed possible-the Press" (p. 2I I), a sure sign that he would find it impossible, as indeed he did. He sees General Grant installed as president, a man who "should have been extinct for ages" (p. 266). At Harvard he discovers history to be a "tangled skein" whose "complexity precedes evolution" (p. 302). Yet the narrator never gives up trying to devise sequences, even though the world seems determined to defeat him. These ruptured sequences suggest that perhaps the most essential part of the dynamo for Adams is not its bipolar configuration or the current that connects the poles but the gap that yawns between them. If the gap were not there, the current could not flow; it is a void as essential to the dynamo's operation as anything explicitly present.

The pattern I want to highlight is a transition from a bipolar to a tripartite construction, with the third part being a rupture or gap. Because a void is normally considered nothing rather than something, transitions to these three-part constructions are often subtle. 
However, their characteristically understated emergence should not mislead us into underestimating their importance. The gaps exercise a powerful attraction on Adams's mind, making them not true absences but, as it were, absent presences. To illustrate the process by which a bipolar construction is transformed into a tripartite structure through the insertion of a gap, consider the interplay between the "larger synthesis" Adams took from Hegel (p. 40r) and the "larger contradiction" he devised as an answer (p. 406).

For Adams the Hegelian dialectic was closely associated with the scientific relativism he found in Henri Poincaré's La Science et l'bypothèse (pp. 454-455). Poincaré pointed out that it was no longer possible, since the advent of non-Euclidean geometry, to ask whether Euclidean geometry was true in any absolute sense. One could ask only if a geometry was consistent, given its axioms. The choice of a geometry was based not on its truth but on its convenience, much as one chooses for convenience a reference point from which other points may be measured. Poincaré saw the development of science in somewhat analogous terms. One accepts at the outset, he argued, that scientific laws are not fixed truths but relative to what is known at the time. If science approaches truth, it does so asymptotically, coming incrementally near but never quite arriving. According to Poincaré, the search for scientific laws proceeds according to a dialectic that alternates between the simple and the complex. When a field of scientific inquiry is new, simple explanations are adequate; as more facts are discovered, explanations grow correspondingly complex. After a sufficient level of complexity is reached, a new synthesis makes things simple again by subsuming previously unassimilated facts into a single explanatory framework. As still more facts are discovered, the tidiness of the theory begins to unravel, until eventually another larger synthesis emerges to "unify the anarchy again" (p. 40I).

While admitting the force of Poincaré's argument, Adams takes issue with the implication that a larger synthesis, by virtue of being more encompassing, represents progress. The deciding factor is the human scale. Adams writes that for "human purposes a point must always be soon reached where larger synthesis is suicide" (p. 402). Against the idea of a "larger synthesis" he poses a "larger contradiction," exemplified in the political party he founds with Bay Lodge, 
the Conservative Christian Anarchists. The party operates according to a dynamic that is dialectical, but with a logic closer to Borges than to Hegel. "By the necessity of their philosophical descent, each member of the fraternity denounced the other as unequal to his loftly task and inadequate to grasp it. Of course, no third member could be so much as considered, since the great principle of contradiction could be expressed only by opposites; and no agreement could be conceived, because anarchy, by definition, must be chaos and collision, as in the kinetic theory of a perfect gas" (p. 406).

Aware that agreement to disagree is still agreement, Adams admits that "this law of contradiction was itself agreement, a restriction of personal liberty inconsistent with freedom; but the 'larger synthesis' admitted a limited agreement provided it were strictly confined to the end of larger contradiction." Within this dialectic, the distinction between order and chaos becomes a personal preference, according to where one chooses to exit from the cycle. For his part, Adams chooses disintegration over synthesis, proclaiming that "in the last synthesis, order and anarchy were one, but that the unity was chaos" (p. 406). Amidst the delight the narrator obviously takes in this paradoxical play, an important modification has taken place almost unnoticed: the bipolar dialectic of Conservative Anarchists has been transformed into the triadic configuration of Conservative Christian Anarchists. Why Christian? What is its function in the dialectic?

Early in The Education, the narrator had commented on the lack of religious intensity in his childhood, attributing it to Boston's feeling that it "had solved the universe; or had offered and realized the best solution yet tried. The problem was worked out." Still he lingers over the problem, commenting that of "all the conditions of his youth which afterward puzzled the grown-up man, this disappearance of religion puzzled him most" (p. 34). Whereas in MontSaint-Michel and Chartres Christianity is a highly charged presence, in The Education it is a lack, an absence. Thus the insertion of "Christian" between "Conservative" and "Anarchist" converts the phrase into a three-part structure marked by a void. The presence of the gap allows for the possibility of a transformation beyond the reflexive, paradoxical circling of Conservative Anarchists.

The significance of this gap is revealed when Adams tries and fails to recover Christianity as a contemporary force. Surveying the medi- 
eval glass and architecture of France, Adams calls himself the "Virgin's pilgrim," seeing himself as a bridge between the era of faith and the contemporary attitude of religious indifference. This bridge collapses, however, when the violent forces of the twentieth century intervene to rupture the connection between Adams and the Virgin. Visiting the cathedral at Troyes, he sees a "bit of paper stuck in a window"; it is a notice of the assassination of V. K. Pleve in St. Petersburg. "The mad mixture of Russia and the Crusades, of the Hippodrome and the Renaissance, drove him for refuge into the fascinating Church of St. Pantaleon nearby. Martyrs, murderers, Caesars, saints and assassins-half in glass and half in telegram; chaos of time, place, morals, forces and motive - gave him vertigo." $\mathrm{He}$ decides that he has to abandon the Virgin. To "what purpose had she existed, if, after nineteen hundred years, the world was bloodier than when she was born? . . . The effort for Unity could not be a partial success; even alternating Unity resolved itself into meaningless motion at last." Then comes the resolve that will shape the remainder of the book. "Every man with self-respect enough to become effective, if only as a machine, has had to account for himself somehow, and to invent a formula of his own for his universe, if the standard formulas failed" (pp. $47 \mathrm{I}-472$ ). The strong sense of forward motion in this passage, of coming to a decision if not an answer, illustrates how the eruption of a gap changes the direction Adams is following.

In The Education, a gap is never merely a void. Rather it is a fold that conceals or a tear that reveals. The fold and the tear, although they may seem at odds, are not contradictory in Adams's usage, for when a fold is unfolded, it reveals a tear in the narrative fabric-and through this gap chaos pours. The attraction Adams feels toward the gap is intensely ambivalent. On the one hand, the encounter with chaos can be excruciatingly painful; on the other, it evokes in him an urgent need to make sense of the universe. If it were not for these ruptures, the text might circle endlessly between the forward chronology of the character and the retrospective backward pull of the narrator, much as it circled between the paradoxical antitheses of Conservative Anarchists. The gaps provide the energy necessary to move the narrative forward in more than the superficial senses provided by elapsed time and a sequential turning of pages.

The gaps, partaking of a double nature in the fold/tear, have mul- 
tiple significations. In some contexts they are associated with the "real" self. I remarked earlier on the complex dynamic of revelation and concealment that characterizes the "real" self, whose presence is constituted through the assertion of its absence. In other contexts, the gap is associated with a woman so desired by the "real" self that the two are inextricable. In still other passages, the gap is an entrance through which chaotic forces pour into the ordered world of the character's certainties.

The chapter called "Chaos" marks Adams's initiation into the agonizing, energizing void for which the gap is the textual signifier. The initiation occurs when he attends his sister Louisa as she lies dying of tetanus. His horror at her suffering is intensified by the contrast between her racking pain and the opulent beauty of the Italian summer outside the sickroom. "Death took features altogether new to him, in these rich and sensuous surroundings. Nature enjoyed it, played with it, the horror added to her charm, she liked the torture, and smothered her victim with caresses." The shock strips from his perception the ordered forms that normally populate it, plunging him into a vision of the universe that he will later associate with the random motion of gas molecules in the kinetic theory of heat. The "stage-scenery of the senses collapsed; the human mind felt itself stripped naked, vibrating in a void of shapeless energies, with resistless mass, colliding, crushing, wasting, and destroying what these same energies had created and labored from eternity to perfect." The normal routine of society is revealed as a "pantomime with a mechanical motion," its "so-called thought merged in the mere sense of life, and pleasure in the sense" (p. 288).

Traveling to the Alps to recover his balance, he finds that for "the first time in his life, Mont Blanc for a moment looked to him what it was-a chaos of anarchic and purposeless forces-and he needed days of repose to see it clothe itself again with the illusions of his senses" (p. 289). At this moment the character's perception merges with the world of the "real" self, for when he senses that he has been surrounded by a kind of stage scenery, he comes close to intuiting his own status as a manikin. The effect is not so much to emphasize the character's artificiality, however, as to reveal the constructed nature of consensual reality, for the theater of stage scenery turns out to be the world we all share.

Many readers have seen in Adams's description of his sister's ag- 
ony the death he does not describe-the suicide of his wife, Marian, who took her own life at age forty-two by swallowing potassium cyanide from her darkroom.' Very probably the bonds that join the "real" self to the woman and to chaos were forged in the crucible of Adams's suffering after his wife's death. Marian's death falls into the twenty-year silence that stretches between the first and second halves of The Education. If we think of this lacuna not only as a bottomless hole into which things disappear but also as a rent from which a resistless, remorseless energy radiates, we can better understand the force that animates the character Adams after he declares himself "dead" following his wife's death (p. 330).

Once the gap opens and chaos begins to pour through, it is only a matter of time until chaos becomes a flooding tide on which the remaining pockets of order float like so many isolated islands. To see how this transformation is embodied in the text's language, compare two passages, one from the opening pages, the other near the end. In the first, in a major statement of his theme, the narrator declares that the "problem of running order through chaos, direction through space, unity through multiplicity, has always been, and must always be, the task of education, as it is the moral of religion, philosophy, science, art, politics, and economy" (p. I2). The lines of sight in this passage run horizontally, an orientation reinforced by the series of parallel phrases. The active principle is order; words associated with chaos are imaged as mere inert media through which direction and unity run. The activity of "running" is, moreover, itself a unifying principle, for it joins in a common endeavor the arts and sciences, as well as the work performed by education (and by implication, The Education).

Contrast these characteristics with a much later passage in which Adams, musing on the new psychology, thinks that it conceives of the mind as a bicycle rider "mechanically balancing himself by inhibiting all of his inferior personalities, and sure to fall into the sub-

'See, for example, Rowe, 1976: 1 16; and Paul Hamill's "Living and Dying in History: Death in The Education of Henry Adams," Soundings 60 (1976): 150-65, especially p. 153. For a speculative treatment of the effect on Adams's writing of his wife's death, see Elizabeth Waterston, “The Gap in Henry Adams's Education," Canadian Review of American Studies 7 (1976): 132-138. The fullest source remains Ernest Samuels, Henry Adams: The Major Phase (Cambridge: Harvard University Press, 1964). 
conscious chaos below, if one of his inferior personalities got on top. The only absolute truth was the sub-conscious chaos below, which everyone could feel when he sought it" (p. 433). Here the lines of sight are vertical, plummeting down into chaos or rising to balance precariously over it. The imagery emphasizes the disjunctions that divide what was a unity into discrete units, all fighting against one another in a cacophony of competing claims - the rider struggling with the bicycle, the bicycle teetering over chaos, the rider divided within himself by warring personalities held only temporarily in check. Instead of parallel phrases, with their suggestion of a broad, stable base, the rhetoric relies on a conjunction that depends on a conditional clause, which is further qualified by the alarming assertion that the "only absolute truth was the sub-conscious chaos below." Although the rider is active to the point of frenzy, the dominant principle, and the force against which he must struggle, is chaos-without and within.

Granted, in this passage Adams is writing about what the new psychology thinks the mind is rather than what he thinks it is. But exposure to chaos in the language of the text does not leave the character Adams unchanged, any more than exposure to chaos in the world has left humankind unchanged. Increasingly as The Education progresses, the character Adams finds himself drawn, through the narrator's rhetoric, into the "void of shapeless energies" that he intuited behind the stage scenery of ordered representations when Louisa died.

The phrase the narrator uses to signify chaos flooding into his text (and into the world) is "supersensual chaos" (p. 45I). The phrase derives from Karl Pearson's Grammar of Science, summarized in the chapter of that name in The Education. According to Pearson, scientific representations are necessarily limited to the realm of sensory impressions. Of the "chaos behind sensations," science can know nothing. In a passage that Adams quotes, Pearson writes "in the "beyond" of sense-impressions, we cannot infer necessity, order or routine, for these are concepts formed by the mind of man on this side of sense-impressions." "The narrator's contribution to Pearson's image is to adjust the scale of proportion, so that the ordered world of human perception appears as a speck floating on an ocean of chaos. The change of proportion is evident in his paraphrase of Pearson's assertion: "Chaos was the law of Nature; Order was the 
dream of man" (p. 45I). The sentence exemplifies the paradoxical play that unites chaos with order, absence with presence in The Education. Read straightforwardly, it asserts that chaos has displaced order as the texture of reality; but in the process chaos has become a law, indicating that chaos itself is a kind of order. Order, for its part, is identified with dream, signifying its unreality. Since the "dream of man" is opposed to the "law of Nature," however, there is also the suggestion that order is the reality we know, whatever the case may be for reality-in-itself.

These implications are made explicit in a longer passage that sums up woman's sense of order, in images that extend and ramify the connotations of a supersensual chaos. "She did not think of her universe as a raft to which the limpets stuck for life in the surge of a supersensual chaos; she conceived herself and her family as the centre and flower of an ordered universe which she knew to be unity because she had made it after the image of her own fecundity; and this creation of hers was surrounded by beauties and perfections which she knew to be real because she herself had imagined them" (p. 459). An unreal order that materializes into presence because it has been imagined; and a chaos that fades into absence because it exists in external reality. The dialectic is the same as that used to constitute the multiple personae of Henry Adams: the character who materializes into a textual presence because he has been imagined; the "real" self who fades into absence because he exists in external reality. It is thus not only through images that chaos and the "real" self are associated. They are also conjoined because they occupy the same structural positions within the dynamics of the text. ${ }^{8}$

${ }^{x}$ The structural connection that The Education posits between the self and the void has a parallel in the psychoanalytic theories of Jacques Lacan, especially in Lacan's assertion that it is the absence of the object that leads a child to desire it, or indeed to recognize it as an object. For Lacan, it "is the world of words which creates the world of things" (Speech and Language in Psychoanalysis, trans. Anthony Wilden [Baltimore: Johns Hopkins University Press, 1981], p. 39). Thus it is only with a child's entrance into language that the world of objects comes into existence. Since the essential psychical dynamics derive from absence rather than presence, it follows that the world of objects is also constituted as a series of successive absences. Presence arrives through metonymic displacement of one absent object by another, just as signification is built upon a chain of signifiers that emerge from a void. Where Adams departs from Lacan is precisely the point that makes The Education of interest for this study-in associating the void with chaos. While recognizing that the parallel with Lacan exists, I prefer to develop my argument about The Education through a vocabulary and a frame of reference closer to Adams's own thinking. 
As Adams the character gets drawn deeper into the gap that is at once chaos and his own mind, he becomes more determined to find a sequence that can connect past to future, self to world, order to chaos. The importance of sequence in establishing a connection between self and the world goes back at least to Descartes. In his I 637 Discourse on Method, Descartes drew a parallel between sequences in Euclidean geometry and the inductive chains of reasoning that allowed him to connect the thinking mind with the outside world. He implied that the self can know the world because reliable sequences can be constructed. "The long chains of simple and easy reasoning by which geometers are accustomed to reach the conclusions of their most difficult demonstrations, led me to imagine that all things, to the knowledge of which man is competent, are mutually connected in the same way, and there is nothing so far removed from us as to be beyond our reach or so hidden that we cannot discover it, provided only we abstain from accepting the false for the true, and always preserve in our thoughts the order necessary for the deduction of one truth from another." "Reading Descartes, one can better appreciate Adams's shock in learning from Poincaré that Euclidean geometry is not true, merely convenient. If geometry is the standard against which the construction of sequence is to be measured, what does it signify that the chains of reasoning Descartes so admired are merely extrapolations from a point chosen because it was convenient?

The task Adams set himself was to wrest from the void a new conception of sequence that would inhere in the very forces that disrupted traditional sequences. Finding that the "sequence of men led to nothing," that the "sequence of time was artificial," and (in a revealing phrase) that the "sequence of thought was chaos," Adams "turned at last to the sequence of force" (p. 382). To make the gap give birth to this new kind of sequence, he refashioned it into an anarchical space crackling with violent energies-an image brought to life by the dynamo. The result was the dynamic theory of history, presented in The Education as Adams's own attempt at a larger synthesis. The theory rewrites the history of humankind as its encounter

${ }^{4}$ Quoted in Morris Kline, Mathematics: The Loss of Certainty (New York: Oxford University Press, 1980), p. 98 . 
with increasingly powerful forces. Sequences are disrupted when a new and more anarchical force enters the stage of human action. Forces can be either physical or spiritual; Christianity qualifies as an epoch-initiating force, along with gunpowder and fire. The theory predicts that the world will end with a bang rather than a whimper, for the process will continue at an accelerating rate until the power of the captured forces exceeds the ability of humankind to control them.

Throughout Adams's account of his dynamic theory, as John Carlos Rowe has noticed, there is a disturbing ambiguity about the direction in which the lines of force run. ${ }^{10}$ We are told, for example, that the dynamic theory "takes for granted that the forces of nature capture man." But within a few lines we are presented with an image that shows man capturing the forces. The theory "may liken man to a spider in its web, watching for chance prey. Forces of nature dance like flies before the net, and the spider pounces on them when it can." Who is in control, man or the forces? "The sum of force attracts; the feeble atom or molecule called man is attracted; he is the sum of the forces that attract him; he suffers education or growth; his body and his thought are alike their product; the movement of the forces controls the progress of his mind, since he can know nothing but the motions which impinge on his senses, whose sum makes education" (p. 474). Adams seems to imply that man only thinks he is capturing forces, whereas in reality they are capturing him; but after the mind and chaos have become sufficiently intertwined, it is difficult to tell which has priority. For if man has become "the sum of the forces that attract him," is he not transfigured into that which shaped him, thus becoming his own origin?

"The universe that had formed him took shape in his mind as a reflection of his own unity, containing all forces except himself" (p. 475). Is this a description of the way the universe interacts with humans? Or of The Education of Henry Adams, whose encyclopedic scope seems to include everything but the "real" Henry Adams? How can we distinguish between a mind formed by a universe of

\footnotetext{
${ }^{10}$ Rowe comments that the "image of the spider and its prey is inverted curiously. In a conventional deterministic scheme, man would be the prey of forces beyond his control. Yet here the forces are the victims of the trap, the mind acting as the weaver of the pattern" (1976:127).
} 
chaotic forces and a mind that is the origin for those same chaotic forces? Consider: the proof that man has been formed by a universe of force is a turning inside out of the human mind, in which it becomes a container for the forces but no longer contains itself. Where in this construction is the self located? Presumably exterior to the mind that contains "all forces except himself." Thus the void becomes the self and the self becomes the void, each occupying the other's former position as if they were the inside and outside surfaces of a Möbius strip. ${ }^{11}$

Implicit in these inversions is a realization central to the pattern I have been describing. The Education of Henry Adams itself embodies the process it describes in the dynamic theory of history. The sequence of the text is established not by Adams's personal history or by the history of his time but by the continual interaction of his mind with the chaotic forces of the void. ${ }^{2}$ Although he resists, at each encounter Adams absorbs more of the chaos within himself, until his mind is sufficiently energized to give form to the chaos without, as he does by postulating the dynamic theory of history. "Clearly if he was bound to reduce all these forces to a common value, this common value could have no measure but that of their attraction on his own mind. He must treat them as they had been felt; as convertible, reversible, interchangeable attractions on thought" (p. 383). The inside/outside inversion that hovers just on the edge of articulation in this passage embodies a profound ambiguity about where the chaos is finally to be located. Once Adams has absorbed enough of it, it becomes he and he becomes it. Ronald Martin, in his fine study American Literature and the Universe of Force (1981), edges toward this realization when he points out that the "Dynamic Theory and the process of its formulation are con-

\footnotetext{
"Jacques Lacan discusses how the inside/outside inversion relates to his construction of self on the basis of absence in "Of Structure as an Inmixing of an Otherness Prerequisite to Any Subject Whatsoever," In The Languages of Criticism and the Sciences of Man: The Structuralist Controversy, ed. Richard Macksey and Eugenio Donato (Baltimore: Johns Hopkins University Press, I970), pp. I 86-200, especially 192.

'G. Thomas Couser, in "The Shape of Death in American Autobiography," Hudson Review 3 I (1978): 53-66, comments that "upon close examination of the theory, we find that in spite of his habitual self-deprecation, Adams put his own consciousness squarely at the center of his own cosmology. . . His formula for the universe and his account of himself were aspects of the same vision" (p. 63).
} 
foundingly metaphorical: the protagonist's career serves as a metaphor for the course of Western civilization, but finally the course of Western civilization serves as a metaphor for the narrator's mind. There is no simple way to take it" (p. I39).

The self-reflexive circling that connects the self to the chaotic void has a moral aspect that is capable of invoking almost palpable pain in the narrator. If Adams has become the chaos he deplores, how can he fix the limits of his responsibility? Contemplating the accelerating forces to which he believes human history is subject, the narrator confesses that "all that a historian won was a vehement wish to escape. He saw his education complete. ... He repudiated all share in the world as it was to be, and yet he could not detect the point where his responsibility began or ended" (p. 458; emphasis added). But perhaps Adams, rather than bringing chaos into the world because his mind attracts it, is merely the instrument of forces that attract his mind. Some of the images suggest this more passive possibility. For example, the narrator, in a continuation of the passage cited earlier on the new psychology, proposes that the new science of the mind sees it as an electromagnet, "mechanically dispersing its lines of force when it went to sleep, and mechanically orienting them when it woke up." He impishly wonders "which was normal, the dispersion or orientation?" (p. 434). The prospect that one's mind is an electromagnet automatically generating lines of force instead of the lines of will Adams resolved to follow in "Darwinism" may not be flattering, but it at least alleviates the sense of guilt.

A more disturbing idea is the inference Adams draws from his dynamic theory, that the "laws of history only repeat the lines of force or thought" (p. 457). If this is true, then Adams's thoughts are partly responsible for bringing into existence a world so chaotic that, by the end, the narrator must wonder whether "sensitive and timid natures could regard [it] without a shudder" (p. 505). The narrator tries hard to maintain his objectivity. Earlier he laid down as an article of faith that no "honest historian can take part withor against-the forces he has to study" (p. 447). But faced with his responsibility for bringing chaos into the world, as his own dynamic theory implies, the narrator admits that "though his will be iron, he cannot help now and then resuming his humanity or simianity in face of a fear." What is this fear? "The motion of thought had the same value as the motion of a cannonball seen approaching the ob- 
server on a direct line through the air. One could watch its curve for five thousand years. Its first violent acceleration in historical times had ended in the catastrophe of $3 \mathrm{IO}$. The next swerve of direction occurred toward I 500 . Galileo and Bacon gave a still newer curve to it, which altered its values; but all these changes had never altered the continuity. Only in I900, the continuity snapped" (p. 457). Toward whom is the cannonball heading now, and what force is directing its path? The narrator's worst nightmare is that the answer to both questions is the same: the mind of Henry Adams. In this vision of terror, Adams cannot escape the cannonball because he cannot elude his own thoughts. More literally, he cannot escape because he is the cannonball. ${ }^{13}$

This nightmare vision explains why establishing the proper sequence is the central problem of The Education. If Adams, like the spider, pounced on the forces, providing first through his consciousness and then through his text the gaps through which it could flood the world, then he must accept responsibility for creating a multiverse he deplores. If, on the contrary, the forces captured him, then he is at most a helpless and passive accomplice to the inevitable. The problem reduces to a question of sequence: did the textual gaps create the chaos that emanates from them, or did the resistless force of chaos create the gaps when it tore the fabric of order and textuality? Everything is made to hang on the answer, from the fate of the world to the moral responsibility Adams must accept in helping to create that fate.

It is not difficult to read into this urgent questioning a hidden agenda for also establishing the extent of his responsibility for the fate of the woman. Pondering on why woman has ceased to be the potent force that Adams believes is her birthright by virtue of her sexual power, the narrator suggests that "at dinner, one might wait till talk flagged, and then, as mildly as possible, ask one's liveliest neighbor whether she could explain why the American woman was a failure. Without an instant's hesitation, she was sure to answer:

${ }^{13}$ I am indebted to Sandra Bernhart, in a paper written for my Adams and Pynchon Seminar at Dartmouth College, $198 \mathrm{I}$, for the suggestion that the cannonball in this passage is Adams's thought. It uncannily looks forward to Pynchon's use of Enzian as a human cannonball in the Rocket. Perhaps the correspondence is not accidental. Pynchon was deeply influenced by The Education of Henry Adams, as both V. and Gravity's Rainbow reveal. 
'Because the American man is a failure!' She meant it" (p. 442). Whether this remark had a deeper personal significance for Adams in view of the tragedy that marked his private life we cannot know, although it is a likely surmise. Within the context of The Education, the woman who most obviously fails because he (and everyone else) has failed her is the Virgin. Like most of the failures in The Education, the Virgin's has an ambiguous value. Although she has ceased to be a force in contemporary society, she nevertheless serves as a reference point from which the force of the Dynamo may be measured. Thus even in her absence, she serves as an anchor for Adams's new kind of sequence. By implication, the woman also serves as a reference point from which the self may measure its responsibility for creating the chaos it abhors.

To make his new sequence work, Adams needs to establish that the units used to measure the two different kinds of forces represented by the Dynamo and the Virgin are equivalent. This means, of course, that he has to find a common measure for mechanical and spiritual (i.e., sexual) attraction. That measure is his mind. "He must treat them as they had been felt; as convertible, reversible, interchangeable attractions on thought. He made up his mind to venture it; he would risk translating rays into faith" (p. 383). The subjectivity that informs Adams's use of metaphor is not merely whimsical, any more than the form of The Education is arbitrary. On the contrary, it is a rigorous working out of the conditions that must obtain if Adams is to create a nontrivial sequence that will connect him to a chaotic multiverse and also allow him to confine chaos within the laws of order. The connection between the "real" self, the woman, and the chaotic void is a knot woven into the very texture of this text. If it were untied, the logic that holds the text together would also unravel.

Through this knot, Adams arrives at a transvaluation of chaos not unlike that the scientific tradition achieved in the century between I 850 and 1950. Although Adams followed a unique route to arrive at his result, there are significant parallels between The Education and the scientific texts. Especially striking is the key role that metaphors play in both transformations. In the scientific texts, metaphors embody connotations not explicitly present in the theories but nevertheless instrumental in guiding their development. In The Education, the connection between metaphors and the underlying thought 
lies much closer to the surface. Metaphors in The Education characteristically act as juncture points between subjective experience and objective reality. Consider, for example, the "Darwinism" chapter as the site of a suture. This chapter introduces two biological termsTerebratula and Pteraspis - that reappear throughout the text, each time with increasing resonance. Tracking the evolution of these terms will illustrate how The Education compounds the subjectivity of its personae with the apparent objectivity of scientific concepts.

We meet the first term, Terebratula (designating a genus of brachiopods), when Sir Charles Lyell tells Adams it is a life form that "appeared to be identical from the beginning to the end of geological time" (p. 228). ${ }^{14}$ Although Sir Charles seems oblivious of the implication that Terebratula contradicts the continuous, unbroken evolution that he champions, to Adams it indicates "altogether too much uniformity and much too little selection" (p. 228). A closely related term is Pteraspis, designating a ganoid fish and "cousin to the sturgeon." Pteraspis, the first vertebrate to appear in the fossil record, resided in a "kingdom . . called Siluria" (p. 229). The narrator calls it "one's earliest ancestor and nearest relative" (p. 228). Like Terebratula, Pteraspis also poses a challenge to Darwinism, for beyond it stretches only a void rather than the graduated development that continous evolution predicts.

Terebratula and Pteraspis reflect the double vision of Adams presented in The Education. ${ }^{15}$ On the one hand the narrator characterizes the young Adams as an antiquated mollusk like the Terebratula, himself unchanging while the world breaks from its moorings around him. On the other hand, Adams the character comes increasingly to suspect that hidden within him is another, catastrophic ver-

\footnotetext{
${ }^{14}$ Edward Morse, a British scientist who traveled to Japan in the 1850 , proved that the Terebratula was in fact not a mussel but a worm. An account of Morse's discovery can be found in Robert A. Rosenstone, Mirror in the Shrine: American Encounters with Meiji Japan (Cambridge: Harvard University Press, 1988). Allusions in The Education suggest that Adams was unaware of the distinction. I am grateful to Professor Rosenstone for showing me pictures of Terebratula, which look like tiny mussels a fraction of an inch in diameter.

"In my analysis of these metaphors, I have drawn on R. P. Blackmur's discussion of them in the chapter called "Terebratula and Pteraspis" in his Henry Adams (1980:62-72). Wayne Lesser also has an illuminating discussion of them in "Criticism, Literary History, and the Paradigm: The Education of Henry Adams," PMLA 97 (1 982): $378-94$.
} 
sion of himself which will emerge like the Pteraspis, rupturing sequence and making continuity with the past impossible. It is no accident that this realization occurs in the chapter where the terms are first introduced. The contradiction between stasis and rupture plays through subsequent uses of the terms, making the supposedly objective reality they represent as convoluted and turbulent as Adams's own subjectivity.

Consider, for example, those instances where the narrator uses the terms metonymically to mark places where sequences should have begun but did not. Despairing of using time as a meaningful sequence, the narrator remarks that he "could detect no more evolution in life since the Pteraspis than he could detect it in architecture since the [Wenlock] Abbey. All he could prove was change" ( $p$. 230). The lack of correlation between time passed and evolution achieved applies also to him. After being in England eight years, he found that he "was already old in society, and belonged to the Silurian horizon" (p. 235). The implication that he belongs to an age discontinuous with the present is confirmed when he arrives in Washington and discovers that the connections his family afforded him are merely the "accumulated capital of a Silurian age. A few months or years more, and they were gone" (p. 252). But the arrival of the new postwar administration with the election of General Grant is so regressive that it makes him look progressive by comparison. "Grant fretted and irritated him, like the Terebratula, as a defiance of first principles. He had no right to exist. He should have been extinct for ages" (p. 266). Embodied in these references is an increasing ambiguity about whether Adams is atavistic or chaotic, moored to the past or already part of a future discontinuous with the present. ${ }^{16}$

"With this nimbus of meaning surrounding the terms, their presence anticipates as well as confirms the confounding of past and future. When Adams is asked to teach history at Harvard, he remarks that "even a Terebratula would be pleased and grateful for a compliment which implied that the new President of Harvard College wanted his help" (p. 29I). The implication is that an unchanging Adams will not be able to teach history effectively, because he cannot establish anything other than the most artificial of sequences. He finds that "nothing is easier than to teach historical method, but, when learned, it has little use. History is a tangled skein that one may take up at any point, and break when one has unravelled enough; but complexity precedes evolution." He is also kept from a view of history as stasis, however, because the "Pteraspis grins horribly from the closed entrance" (p. 302). 
Another cluster of references comes in the "Twilight" chapter when Adams, convinced that the confounding of sequence is pervasive in his own life, looks to science to verify that ruptured sequences are objectively true as well. He returns to biology to discover "what had happened to his oldest friend and cousin the ganoid fish, the Pteraspis of Ludlow and Wenlock, with whom he had sported when geological life was young; as though they had all remained together in time to act the Mask of Comus at Ludlow Castle, and repeat 'how charming is divine philosophy!'” (p. 399). Predictably, he finds that, although an ancestry has been discovered for Pteraspis in the Colorado limestone, the field of geology is in a state of confusion that surpasses his own. "The textbooks refused even to discuss theories, frankly throwing up their hands and avowing that progress depended on studying each rock as a law to itself" (p. 40I). The narrator is not optimistic that some new theory will arrive to make sense of the contradictions. All that he can be sure of is "rapidly increasing complexity," although he wonders if "the change might be only in himself" (p. 402).

The compounding of past and future, stasis and rupture, becomes explicit in the brilliant artifice of the paradoxes that glitter at the end of the "Twilight" chapter. Intuiting that he is himself an instigator of the change he loathes, the narrator longs to "begin afresh" with ancient life forms in prehistoric waters, "side by side with Adamses and Quincys and Harvard College, all unchanged and unchangeable since archaic time." But then he realizes that if change has indeed originated within him, stasis is doomed in any event, even if he could return to the beginning. Somehow the rupture was forecast at the beginning, even as the stasis of the beginning lingers as a longing for return after the rupture has occurred. He concludes that a "seeker of truth-or illusion-would be none the less restless, though a shark!" (p. 402). The sentiment serves as conclusion for the chapter and marks a moment in the text when no sequence connecting past and future seems possible, except the sequence established by the repeated and pervasive failure of all previous sequences.

The patterns formed by this evolving network of references demonstrate how profoundly Adams merges technical denotation with the deeper thematic and psychological dynamics of his text. Once 
chaos and contradiction are recognized as important constituents of subjectivity, it is imperative to Adams that they be present in objective reality as well. Only thus can his consciousness be joined to the multiverse that he believes represents the world as it is or will be. To admit the possibility that science could demonstrate that the multiverse was in fact a universe, or that objective reality was ordered, would in the face of a chaotic subjectivity be an invitation to solipsism, if not to unrelievable guilt.

William Jordy, in his definitive study Henry Adams: Scientific Historian (1952), shows how Adams systematically distorted and misrepresented the scientific evidence to make sure that the correlation between his chaotic subjectivity and a chaotic world would obtain. But Adams was premature in his judgment that science was in disarray. Even as he was writing The Education, one of the most successful of science's larger syntheses had already been publishedEinstein's special theory of relativity. It would be another quarter of a century before the new synthesis began to unravel again with quantum mechanics, and a half century before the chaos that so preoccupied Adams would become important in scientific theorizing.

Perhaps the most puzzling of Adams's scientific (mis)appropriations is his vision of chaos as an energizing force capable of stimulating self-organization and increasing complexity. Granted, complexity did not have for Adams the entirely positive connotations it has in contemporary scientific discourse. Nevertheless, in seeing that chaos could be linked to the emergence of complex systems, Adams did envision chaos very differently than had Kelvin or even Boltzmann. Yet a mere three years after he had completed The Education, Adams published "A Letter to American Teachers of History" (I9IO), in which he used classical thermodynamic arguments to demonstrate that the world and human intellect were running down. The sophisticated reasoning characteristic of the modern mind represented an entropic decline; the high point for the human race had come in the Middle Ages, before instinct had wholly given way to reason. ${ }^{17}$ How could he espouse this entropic view of history when

${ }^{17}$ John J. Conder, in A Formula of His Own: Henry Adams's Literary Experiment (Chicago: University of Chicago Press, 1970), argues that the decline from instinct to reason forms the structural principle for all of Adams's late works, including The Education. To my mind, this orientation causes Conder to misread some parts of 
he so recently had worked out the implications of an accelerating view in The Education?

As Jordy points out, it is possible to reconcile the entropic and accelerating views if one assumes that intellectual speculation and physical energy can be equated, and that both operate within a closed system (I952: I 58-219). If humans are thinking in ever more complex ways, they are presumably depleting their store of intellectual energy at increasing rates, and thus declining faster and faster even while they appear to be accelerating. Of course, the premise that human evolution takes place within a closed system is incorrect. Life is possible only because our planet receives massive doses of energy from the sun every day. Similarly, the assumption that intellectual and physical energy can be equated is at the very least extremely problematic, as Professor Henry A. Bumstead of Yale informed Adams when he was asked to respond to a manuscript draft of "The Rule of Phase Applied to History."

After receiving Bumstead's criticism in January I9 Io, Adams made only small revisions in "A Letter to American Teachers of History" before mailing it out to college presidents, professors, and libraries in the spring of rgro. Later that year he revised "A Rule of Phase Applied to History" (originally published in 1909), taking into account some of Bumstead's corrections but allowing the central thesis to stand. ${ }^{18}$ It is possible that Adams simply did not understand the gravity of Bumstead's objection that thought and energy cannot be equated. So customary-and necessary-was his compounding of human consciousness with the supposedly objective world of chaotic force that for him to take full account of it would have required a complete reorientation of his thought - a task that, at age seventy-two, he may well have been unable as well as unwilling to undertake.

The Education where infolded complexity is most apparent, such as the "Darwinism" chapter. Nevertheless, his study is valuable in highlighting those aspects of The Education that forecast most clearly the entropic view of the later works.

${ }^{18} J o r d y(1952)$ has a full discussion of Bumstead's criticism and the chronology of revisions (pp. I52-I53, 273ff). Both "A Letter to American Teachers of History" and "The Rule of Phase Applied to History" were published by Brooks Adams, with an introduction, in The Degradation of Democratic Dogma (I 9 I9). 
Ronald Martin, reviewing the evidence of the manuscript revisions and the Bumstead comments, concludes that Adams's "grasp of modern science does seem to have been as weak as he claimed it was." "Martin argues that the contradiction between the self-organizing view of chaos in The Education and the entropic view of it in the later scientific essays, although so obvious that it could scarcely be missed, was of little or no consequence to Adams. "It did not seem to bother him that instead of the universe accelerating itself to its death in an explosion of etherealization ... it now promised to degrade itself into a dead ocean of entropy. What mattered was that the end be reputably scientific and that it be soon" (1981:143).

Martin may well be correct as far as Henry Adams, the historical figure, is concerned. However, for the text of The Education and the multiple personae called Henry Adams constituted within it, it makes all the difference that chaos is conceived as capable of creation as well as destruction. It is this ambiguity that authorizes the narrator to dream he might be drawn into the gap and find there an equi/multivocal unity amidst his multiple selves and the world. "There is nothing unscientific in the idea that, beyond the lines of force felt by the senses, the universe may be-as it has always been-either a supersensous chaos or a divine unity, which irresistibly attracts, and is either life or death to penetrate" (p. 487 ). It is this ambiguity that allows him to imagine the child of the twentieth century as "a sort of God compared with any former creation of nature" (p. 497). And finally, it is this that encourages him to imagine that he and his two closest friends, united in 1938 on the centenary of their births, "might be allowed to return together for a holiday, to see the mistakes of their own lives made clear in the light of the mistakes of their successors; and perhaps then, for the first time since man began his education among the carnivores, they would find a world that sensitive and timid natures could regard without a

\footnotetext{
"To illustrate Adams's scientific ineptitude, Martin points out that he "needed to be told such things as that the terms 'movement,' 'velocity,' and 'acceleration' are not roughly synonymous; that potential energy is not concealed kinetic energy; that some connections Adams calls 'logical' are really analogical; that light is not polarized by a magnet; that entropy is not merely deadness; that 'lines of force' are not a physical reality; that Adams applied what he called 'the law of inverse squares' incorrectly, and that he even neglected to figure it inversely" (1981:142).
} 
shudder" (p. 505). However qualified and ironic this hope for a better world is, it is an improvement over the narrator's earlier vision of himself, alone, facing the plummeting cannonball that is also his thought.

In light of Adams's scientific inaccuracies, it would be misleading to picture him as a prophetic thinker who anticipated the science of chaos when scientists themselves were only beginning to understand the limitations of the Newtonian paradigm..$^{20}$ Rather, his importance for this study lies in the subtle and complex connections he established between chaos and the way the self is constituted within language and literature. In associating the self with absence rather than presence, he negotiated some of the same territory that would later be staked out by such seminal theorists as Lacan and Derrida. In connecting this problematic self to chaos, he devised strategies of representation that foreshadowed the work of such important contemporary writers as Stanislaw Lem, Doris Lessing, and Italo Calvino. One of the punning connections that Adams was fond of making in The Education was between his name and Adam, first man on earth. The pun expressed his rootedness in the past and, increasingly as The Education progressed, the fear that he himself was the catastrophe that severed past from future. From our perspective, the chaos that tore him from his roots is also the thread connecting him to the future he dreaded and anticipated. It is an irony he would have appreciated.

"Paul Hamill, in "Science as Ideology: The Case of the Amateur, Henry Adams," Canadian Review of American Studies I2 (198I): 2 I-35, defends Adams's use of science by arguing that the "scientific ideas that engaged him were those that still possessed an unexplored metaphorical dimension for scientists too. No one was entirely sure how far a strictly scientific understanding of evolution or entropy could be extended to explain human life and culture" (p. 23). I concur; but this is different from saying that Adams foresaw the scientific theories. Ernest Samuels, in his summary article "Henry Adams: I838-I9I 8," in Harbert, I98 I:84-IO3, comments that although we cannot take the science of The Education seriously, Adams shows "virtuosity" in manipulating the new concepts, demonstrating that "a new field of metaphor is available to the literary artist and that scientific reality can add a new idiom to poetry" (pp. Io2-133). 